\title{
Fractura de Segond: diagnóstico por resonancia magnética
}

\author{
Segond's fracture: MRI diagnosis \\ Héctor Mauricio Bazaldúa Cheda, * René Machorro Atempa, * \\ José Alejandro Castillo García, * María de Guadalupe Gómez Pérez ${ }^{\ddagger}$
}

La fractura de Segond se define como una avulsión ósea de la inserción tibial del ligamento anterolateral (LAL), el cual se origina en el epicóndilo femoral lateral y se inserta en la tibia anterolateral, mostrando adherencias firmes al cuerpo del menisco lateral a lo largo de su curso oblicuo en la cara lateral de la rodilla. Es bien reconocida la asociación entre la fractura de Segond y daño grave intraarticular (en especial de ruptura del LCA), por lo que, ante este hallazgo por radiografía, debemos profundizar la evaluación realizando una resonancia magnética para evaluar la extensión de la lesión.

\section{CASO CLÍNICO}

Masculino de 32 años, el cual refiere dolor agudo y edema localizado en la rodilla derecha secundario a rotación interna e hiperextensión al practicar fútbol soccer. Acude al servicio de urgencias donde se solicitan proyecciones radiográficas anteroposterior y lateral de rodilla derecha, identificando una imagen radiopaca vertical, localizada adyacente al borde tibial lateral, en relación a fractura por avulsión (Figura 1). Se complementa estudio con resonancia magnética en la cual se demuestra una ruptura completa del ligamento cruzado anterior (LCA) y del retináculo lateral, confirmando la fractura por avulsión de la meseta tibial a nivel de la inserción del ligamento anterolateral (LAL) (Figura 2).

La descripción original de esta fractura fue realizada por un cirujano francés, Paul Segond, en su estudio sobre el origen de la hemartrosis traumática después de un esguince. El hallazgo principal de su estudio fue la de una estructura anterolateral de la rodilla, la cual presentaba una inserción ósea en la tibia y que, al aplicar movimientos forzados de inversión, se generaba una avulsión ósea a este nivel. ${ }^{1}$ Esta fractura ha sido nombrada posteriormente con su nombre.

Recientemente, se ha descrito su asociación con la inserción tibial del LAL, la cual se origina en el epicóndilo femoral lateral y se inserta en la tibia anterolateral, mostrando adherencias firmes al cuerpo del menisco lateral a lo largo de su curso oblicuo en la cara lateral de la rodilla. ${ }^{2}$ El LAL es la única estructura que se inserta en la posición donde se produce la avulsión ósea, fractura de Segond. ${ }^{3}$ La lesión generalmente implica una rotación interna asociada con estrés en varo, la cual produce dicha avulsión cortical.

Una fractura de Segond es patognomónica de ruptura del LCA, por lo que ante este hallazgo por radiografía, es

\section{Figura 1:}

Radiografía anteroposterior de rodilla derecha. Se identifica fractura por avulsión a nivel de la misma tibial lateral mostrando una fractura de Segond (flecha).

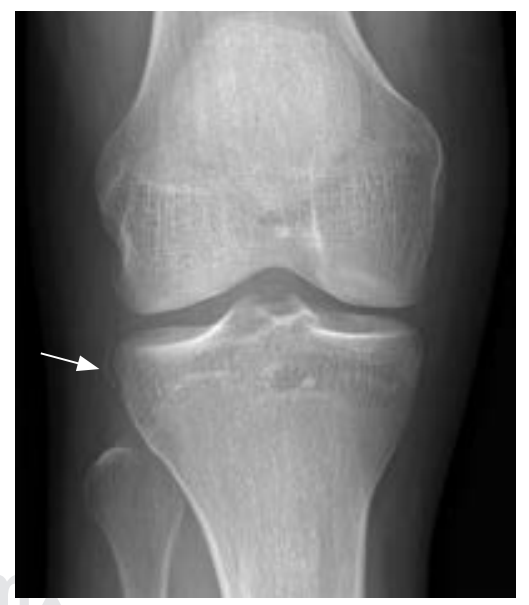

\footnotetext{
* Médico residente.

‡ Profesora titular.
}

Resonancia Magnética, Hospital Ángeles Pedregal. Universidad Nacional Autónoma de México.
Correspondencia:

Dr. Héctor Mauricio Bazaldúa Cheda Correo electrónico: hector_bazal@hotmail.com

Aceptado: 08-08-2019. 

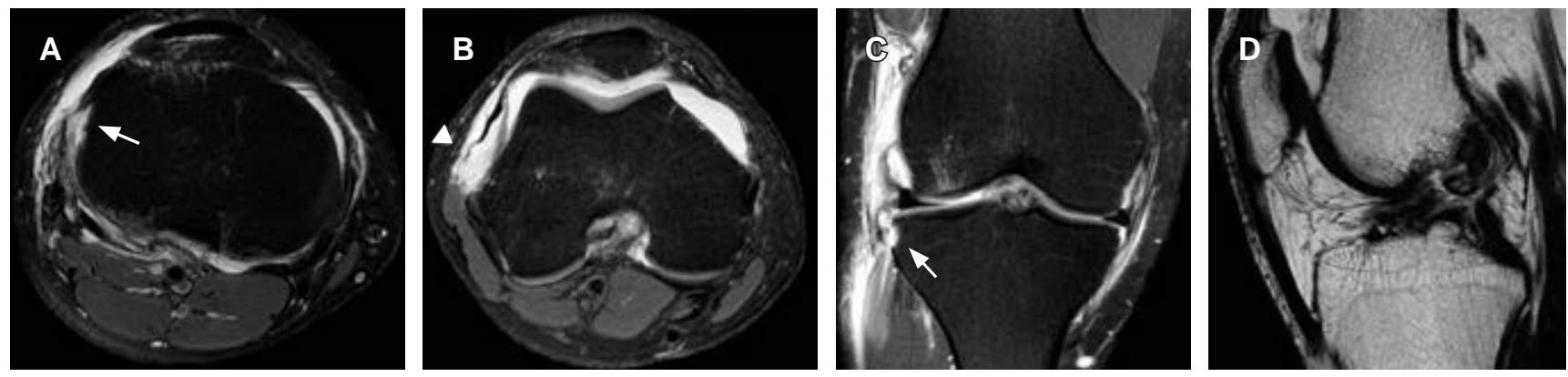

Figura 2: A y B) Axial T2W FS. A) Avulsión ósea a nivel de la inserción tibial del ligamento anterolateral (flecha). B) El retináculo lateral muestra pérdida de su tensión y elongación en relación a ruptura completa (punta de flecha) en su inserción femoral. C) Imagen coronal T2W FS en la cual se delimita el ligamento anterolateral en su inserción femoral, meniscal, y a nivel de la inserción tibial (flecha) con fragmento óseo avulsionado (fractura de Segond). D) Sagital T2SE. Ruptura completa del ligamento cruzado anterior.

necesario profundizar la evaluación realizando una resonancia magnética para evaluar la extensión de la lesión. ${ }^{4}$

\section{REFERENCIAS}

1. Murgier J, Devitt BM, Sevre J, Feller JA, Cavaignac E, et al. The origin of the knee anterolateral ligament discovery. a translation of segond's original work with commentary. Arthroscopy. Arthroscopy. 2019; 35 (2): 684-690.
2. Claes S, Luyckx T, Vereecke E, Bellemans J. The Segond fracture : a bony injury of the anterolateral ligament of the knee. Arthroscopy: The Journal of Arthroscopic and Related Surgery. 2014; 30 (11): 1475-1482.

3. Dodds AL, Halewood C, Gupte CM. The anterolateral ligament anatomy, length changes and association with the Segond fracture. Bone Joint J. 2014; 96-B: 325-331.

4. Cosgrave $\mathrm{CH}$, Burke NG, Hollingsworth J. The Segond fracture: a clue to intra-articular knee pathology. Emerg Med J. 2012; 29(10): 846-847. 